\title{
Mathematics Anxiety and Other Psycho Didactic Aspects in University Students
}

\author{
Valéria ŠVECOVÁ \\ Department of Mathematics \\ Faculty of Natural Sciences \\ Constantine the Philosopher University in Nitra \\ Slovakia
}

\begin{abstract}
In Slovakia there is no research into mathematical anxiety and its impact on mathematics. Our goal was to create a tool for measuring mathematical anxiety that would be adapted to Slovak conditions. Our research studied the relationship between individual need for cognitive structure and three forms of anxiety (math, state, and trait). The sample comprised 184 students of two specializations from the Faculty of Education (63 students of primary education - UPV and 121 students of pre-school and elementary education - PEP). We focused on the performance in the Fractions Test, PNS, STAI, and original version of the math anxiety scale (Sarmány-Schuller, \& Švecová, 2017). We established the level of the mathematical performance in fractions (MPF) latent variable for every student. We calculated correlations between individual variables (MPF, DFS, RLS, M-Anxiety, SAnxiety, and T-Anxiety) for each group of students. The results show significant differences in the mean values of latent variables between groups (PEP and UPV), UPV students achieved statistically more significant results in $M P F$. There were no statistically significant differences in other variables. It is noteworthy that UPV students showed lower need for structure and mathematical anxiety but showed higher degree of anxiety.
\end{abstract}

Keyword: math anxiety, personal need for structure, mathematics

\section{Introduction}

Mathematics anxiety as a negative affective response to math-related situations is a real problem today. As stated by Richardson and Suinn (in Pradeep, 2011), mathematical anxiety includes feelings of tension and anxiety associated with manipulation of numbers and solving mathematical problems in a wide range of situations in ordinary life or academic situations. Mathematical anxiety is a feeling of tension, fear or fear that crosses with mathematical performance. The present research attempts to study the relationship between the mathematical anxiety among high school students and their self-esteem and teachers' personality characteristics. From among the high school students some 480 people were chosen categorically in accordance with their characteristics and 60 mathematics teachers were also chosen through this method. The data were collected using self-esteem questionnaire of Cooper Smith and Mathematics Anxiety Questionnaire and personality questionnaire by Neo. After data analysis, the following findings were concluded: There is negative significant relationship between the students, mathematical anxiety and their self-esteem. There is also a significant relationship between the students, mathematical anxiety and their teacher's personality characteristics. There is no significant relationship between the high school student's mathematics anxiety and their educational levels. There is a significant difference between the mathematical anxiety of moreover students majoring in humanities and natural science students and the students of physics and mathematics students. There is a significant difference between the mathematics anxiety of male and female students.

Several studies suggest that mathematical anxiety interferes with cognitive processing by reducing memory capacity (Ashcraft, 2001). Pradeep (2011) synthesises the various definitions into one and states that it is a state of discomfort, fear of working with numbers, and fear of solving mathematical problems that lead to aversion and avoidance of mathematics and any situation with mathematics connected. The causes of mathematical anxiety may also be inconvenience at school, such as student attendance, which will solve an example of a more rapid, negative reaction of a teacher to a pupil, such shifting behaviour being transferred to math activities only when waiting for an hour and increasing age, mathematical anxiety (Nolting, 2002). 
Potential causal factors can be divided into environmental variables such as negative classroom and teacher experience, intellectual variables, e.g. the degree of abstract and logical thinking and, of course, personality variables, where we can include self-esteem, learning style, attitudes, and so on (Yüksel-Şahin, 2008, Newstead, 1998). The variable of self-sufficiency gained attention in the process of acquiring mathematical knowledge, skills and competencies. Individuals with high self-esteem are expected to have a low degree of mathematical anxiety, which can be more successful. (Brown, 2008). Even in previous research, the relationship between selfesteem and stereotypes in social situations has been found (Levy et al., 1998). However, as suggested by Ashcraft and Kirk (2001), a memory deficit model that is generated by them does not need to capture cognitive processes that imply that even mathematically talented students may not achieve sufficient results if their work memory is temporarily paralysed. In such cases, there may be a situation that even a mathematician student gets a subjective feeling that mathematicians do not understand that the curriculum does not. In international research, one of the tools for measuring mathematical anxiety is the MARS scale (The Mathematical Anxiety Rating Scale) or AMAS (The Abbreviated Math Anxiety Scale). From the above, it follows that the influence of mathematical anxiety, cognitive styles on mathematical success is international research. In our opinion, in Slovakia, a standardised instrument for measuring mathematical anxiety is absent.

Our research studied the relationship between individual need for cognitive structure and three forms of anxiety (math, state, and trait). The sample comprised 184 students of two specializations from the Faculty of Education (63 students of primary education - UPV, average age 23,4 and 121 students of pre-school and elementary education - PEP, average age 19,7).

They are future primary school teachers. Since mathematics is one of several subjects (important in the study) considered it as difficult. We have assumed increased mathematical anxiety in this sample.

\section{Methods}

We focused on the performance in the Fractions Test (Pantziara, \& Phillipou, 2012, Slovak version), PNS, STAI, and original version of the math anxiety scale (Sarmány-Schuller, \& Švecová, 2017).

\section{Fraction test}

The researches Pantziara and Philippou (2012) proposed a test for identification of the level of pupils' conception of fractions. The test consists of 21 tasks in seven groups (1-7) and columns (A, B, C) which represent each level of Sfards' theory of reification (e.g. task B2 represents part-whole subconstruct of fractions in condensation level of fractions' understanding).

The aim of Pantziara \& Phillipou (2012) was to develop and validate a test measuring student' mathematical performance in fractions (MPF), especially part-whole and measure subconstruct, along Sfard's framework. The choice of these two subconstructs was based on research (Charalambous \& Pitta-Pantazi, 2007; Hannula, 2003; Ni 2001). This research was based on Kieren's theoretical model of fraction concept.

The test consisted of 21 tasks in seven triads reflecting understanding at each stage of Sfard's scheme in the two fraction subconstructs and the three operations respectively. Students' solutions were encoded binary ( 0 if the solution was wrong, 1 if the solution was correct).

Pantziara \& Phillip (2012) used the Rasch model to analyse the fraction test. Before using the test in our terms, we have modified some of the tasks. From the other analyses, we excluded the B6 item where the respondents had two ways to compare a pair of fractions. This reasoning is relatively unusual in our circumstances. We also excluded the $\mathrm{C} 1$ item at Pantziara.

We evaluated the data by the IRT model.

\section{PNS scale}

The PNS scale (Personal Need for Structure) by Thompson, Naccarato \& Park (Thompson et al., 2001; Neuberg \& Newsom, 1993) is a six-point self-report scale where participants express of agreement with statements oriented on structuredness of environment. The scale consisted of 11 items and required the participants to answer using a 6-point Likert-scale, with response option ranging from ,strongly disagree" to „strongly agree”. Even though the original scale integrated 12 items, the authors followed Neuberg \& Newsom's (1993) recommendation and omitted Item 5 because of its possible misinterpretation. After excluding item 5 (Neuberg \& Newsom, 1993) the scale consists of 11 items. Items 2, 6 and 11 are inversely scored. 
Švecová et al. (2016), Munková et al. (2014) devoted to PNS research in education.

\section{STAI}

The STAI, or State-Trait Anxiety Inventory (STAI) is an instrument that quantifies adult anxiety (a children's version is also available). This instrument is used to simplify the separation between state anxiety and trait anxiety, feelings of anxiety and depression. The State Anxiety Scale (S-Anxiety) evaluates the current state of anxiety, asking how respondents feel "right now," using items that measure subjective feelings of apprehension, tension, nervousness, worry, and activation/arousal of the autonomic nervous system. The Trait Anxiety Scale (TAnxiety) evaluates relatively stable aspects of "anxiety proneness," including general states of calmness, confidence, and security. The STAI includes 40 questions. This test is split into the S-Anxiety scale and the TAnxiety scale, each having 20 items. These tests are answered based on a 1-4 scale, with the focused areas including: worry, tension, apprehension, and nervousness.

\section{Math Anxiety Questionnaire}

The math anxiety scale consisted of 9 items (M1-M9) and the value of mathematical anxiety we determined the sum of the scores in each item. Questionnaire concerns how student's experience some school situations related to mathematics. Students circle the numbers that best describe their experiences and feelings in different situations according to the corresponding key: (1. no anxiety, 2. very little anxiety, 3. moderate (uncomfortable) anxiety, 4. great anxiety). Situations from the questionnaire are shown in Table 1.

Table 1 Math anxiety questionnaire (MAQ)

\begin{tabular}{|c|c|c|c|c|}
\hline I can't use a prepared formula or a calculator & 1 & 2 & 3 & 4 \\
\hline I am thinking about the math test, which awaits me the next day & 1 & 2 & 3 & 4 \\
\hline I am writing an exam in mathematics & 1 & 2 & 3 & 4 \\
\hline I have an oral exam in mathematics & 1 & 2 & 3 & 4 \\
\hline $\begin{array}{l}\text { I have to write a seminar paper in mathematics, in which we have to solve several challenging } \\
\text { problems }\end{array}$ & 1 & 2 & 3 & 4 \\
\hline I listen a lecture in mathematics intentlyand I don't understand it & 1 & 2 & 3 & 4 \\
\hline I have to go to the blackboard in the mathematics seminar/class & 1 & 2 & 3 & 4 \\
\hline I have to study mathematics problem alone at home & 1 & 2 & 3 & 4 \\
\hline I have to study a new chapter from my mathematics textbook & 1 & 2 & 3 & 4 \\
\hline
\end{tabular}

Reliability analysis conducted on the Math Anxiety Questionnaire yielded a Cronbach's alfa of 0.83 .

\section{Results}

We used Item Response Theory for the fractions test, where the most appropriate appeared to be the Rasch model, and for the PNS the most appropriate model was the correlated traits model (between-item multidimensional IRT model). We established the level of the mathematical performance in fractions (MPF) latent variable for every student. We calculated correlations between individual variables (MPF, DFS, RLS, M-Anxiety, S-Anxiety, and TAnxiety) for each group of students (PEP and UPV- Table2). Table 2 shows the positive correlations between Manxiety and $S$ - anxiety $(\mathrm{p}<0,05)$. 
Table 2. Correlation between variables

\begin{tabular}{lllllll}
\hline PEP & & & & & & \\
\hline & MPF & DFS & RLS & M-Anxiety & S-Anxiety & T-Anxiety \\
\hline MPF & 1 & $-0,17$ & $-0,12$ & $-0,05$ & 0,10 & 0,15 \\
DFS & $-0,17$ & 1 & $0,85^{* * *}$ & $-0,01$ & 0,13 & 0,10 \\
RLS & $-0,12$ & $0,85^{* * *}$ & 1 & $-0,05$ & 0,13 & 0,05 \\
M-Anxiety & $-0,05$ & $-0,01$ & $-0,05$ & 1 & $0,25^{*}$ & 0,10 \\
S-Anxiety & 0,10 & 0,13 & 0,13 & $0,25^{*}$ & 1 & $0,53^{* * *}$ \\
T-Anxiety & 0,15 & 0,10 & 0,05 & 0,10 & $0,53^{* * *}$ & 1 \\
\hline UPV & & & & & & \\
\hline & MPF & DFS & RLS & M-Anxiety & S-Anxiety & T-Anxiety \\
\hline MPF & 1 & $-0,17$ & $-0,11$ & 0,20 & 0,01 & $-0,19$ \\
DFS & $-0,17$ & 1 & $0,81^{* * *}$ & $-0,19$ & 0,06 & 0,19 \\
RLS & $-0,11$ & $0,81^{* * *}$ & 1 & $-0,04$ & 0,17 & 0,24 \\
M-Anxiety & 0,20 & $-0,19$ & $-0,04$ & 1 & $0,39 *$ & 0,10 \\
S-Anxiety & 0,01 & 0,06 & 0,17 & $0,39 *$ & 1 & 0,49 \\
T-Anxiety & $-0,19$ & 0,19 & 0,24 & 0,10 & 0,49 & 1 \\
\hline
\end{tabular}

$(\mathrm{p}<0,001(* * *), \mathrm{p}<0,01(* *), \mathrm{p}<0,05(*))$

Research on state anxiety and performance on complex tasks mostly assumes a curvilinear relationship according to the Yerkes-Dodson law. Here, an intermediate level of stress produces optimal performance, whereas extremely low and high levels of stress produce poor performance. It seems that intrinsic motivation changes the relationship between math anxiety and performance. In studies with children and adults, a linear, negative correlation between math anxiety and performance was found for learners with low levels of motivation and a curvilinear correlation for learners with high levels of motivation in math. For learners with high intrinsic motivation, a moderate degree of math anxiety may have beneficial effects (Hoorfar \& Taleb, 2015). Similar research also dealt with Sarmány-Schuller, Švecová \& Rybanský (2018).

The comparison of latent variables was performed by a multidimensional variance analysis (MANOVA). The results show that average latent variables vary between groups (PEP, UPV) $(F(6 ; 116)=3.43, p=0.003)$ ). Subsequently, one-way ANOVA found that UPV students achieved statistically significantly better results for $\operatorname{MPF}(\mathrm{F}(1 ; 121)=11.21 ; \mathrm{p}=0.001))$.

The results show significant differences in the mean values of latent variables between groups (PEP and UPV), UPV students achieved statistically more significant results in MPF. It is noteworthy that UPV students showed the lower need for structure (DFS and RLS) and mathematical anxiety (M-Anxiety) but showed a higher degree of anxiety (S-Anxiety and T-Anxiety).

The MAQ results can be found: 19 students (4 PEP, 15 UPV) are characterized by low mathematical anxiety (scores of 18); 105 students (70PEP, 35 UPV) by with moderate (uncomfortable) anxiety (score 19-27) and 60 students (46 PEP, 14 UPV) with a high level of mathematical anxiety. We see that $38 \%$ of students PEP and $32 \%$ of all students feel great math anxiety, which we consider to be worrying and also reflect on the results of mathematics. Thisis also one of the reasons why UPV students achieve better results in the MPF.

\section{Discussion}

The research was aimed at finding relations between mathematical knowledge and cognitive-individual variable. Several studies suggest that mathematics anxiety is more closely related to other measures of anxiety, especially test anxiety, than to measures of academic ability and performance (Hembree, 1990; Ashcraft et al., 1998). A positive correlation between M-anxiety and S-anxiety was confirmed in our research too. The UPV students showed lower need for structure. We assume that this is related to the fact that the effects of need for structure vary by age (Kossowska et al., 2012). 
UPV students have achieved statistically significant results in the MPF, apparently related to their better math experience. Similar research by Burns \& Isbell (2007) indicating that math anxiety and the tendency to oversimplify mathematical concepts covary could potentially reveal one mechanism whereby cognitive coping strategies hinder demonstrated math ability. This research also examined the extent to which the provision of tasks designed to expose students to slowly increasing, incremental levels of difficulty might promote the adoption of more accurate cognitive processing strategies. In further research, we would like to focus on mathematical anxiety and its impact on mathematical performance in pupils and students at elementary and secondary schools.

\section{Acknowledgement}

The research leading to these results has received, within the Scientific Grant Agency of the Ministry of Education, Science, Research and Sport of the Slovak Republic and the Slovak Academy of Sciences Grant Agreement VEGA 1/0948/16 for project "The impact of personal need for structure and psycho didactics aspects of the development of mathematical competencies" and VEGA 1/0149/18 "Conceptualization of Fractions in Relation to Personal Need for Structure"

\section{References}

Ashcraft, M. H. (2002). Math anxiety: Personal, educational, and cognitive consequences. In: Current Direction in Psychological Science, 11, 181-185.

Ashcraft M. H., Kirk E. P., \& Hopko D. (1998). On the cognitive consequences of mathematics anxiety. In C. Donlan (Eds.), The Development of Mathematical (pp.175-196). Hove: Erlbaum.

Ashcraft, M. H., \&Kirk, E. (2001). The relationship among working memory, math anxiety and performance. Journal of Experimental Psychology, 130, 224-237.

Brown, H.D. (2000). Principles of language learning and teaching. (4th ed). New York: Addison Wesley Longman.

Burns, K. C., \& Isbell, L. M. (2007). Promoting malleability is not one size fits all: Priming implicit theories of intelligence as a function of self-theories. Self and Identity, 6, 51-63.

Hembree R. (1990). The nature, effects and relief of mathematics anxiety. J. Res. Math. Educ., 21, 33-46.

Hoorfar,H., \& Taleb, Z. (2015)Correlation Between Mathematics Anxiety with Metacognitive Knowledge. Procedia Social and Behavioral Sciences, 182, 737-741.

Kossowska M., Jaśko K., Bar-Tal Y., \& Szastok M. (2012). The relationship between need for closure and memory for schema-related information among younger and older adults. Neuropsychol. Dev. Cogn. B Aging Neuropsychol. Cogn., 19 283-300.

Levy, S. R., Stroessner, S. J., \& Dweck, C. (1998). Stereotype formation and endorsement: The role of implicit theories. Journal of Personality and Social Psychology, 74, 1421-1436.

Munková, D., Stranovská, E., Sarmány Schuller, I., \& Müglová, D.,2014 Personal Need For Structure And Reading Comprehension In A Foreign Language, Studia Psychologica, 56 (3) , p. 199-214.

Neuberg, S. L., \& Newsom, J. T. (1993). Personal need for structure: Individual differences in the desire for simpler structure. Journal of Personality and Social Psychology, 65, 113-131.

Pantziara, M.C., \& Philippou, G. (2012). Levels of Students' "Conception" Of Fractions. Educational Studies in Mathematics, 79, 61-83.

Newstead K. (1998). Aspects of children's mathematics anxiety. Educ Stud Math. 36, 53-71.

Nolting, P.D. (2002). Winning at Math: Your Guide to Learning Mathematics Through Succsefull Study Scills.Bradenton: Academic Success Press.

Pradeep, R. (2011). A Study of Mathematics Anxiety Amongst Primary Pre-service Teachers enrolled in a Dutch Teacher Training Program. [Online]. Available: //esc.fnwi.uva.nl/thesis/centraal/files/f485290306.pdf (November 23, 2017)

Sarmány-Schuller, I., Švecová, V., \& Rybanský, L. (2018). Is there connection among personal need for cognitive structure and math and state and trait anxiety? Poster presented at 39th STAR Conference, Stress, Anxiety and Resilience, The John Paul II Catholic University of Lublin, 2018 July 10-13, Lublin, Poland, Book of Abstracts, Wydawnictwo KUL, Lublin 2018, pp. 175-176

Švecová, V., \& Pavlovičová, G. (2016). Screening the Personal Need for the Structure and solving word problems with fractions. SpringerPlus, 5, 1-9.

Thompson, M. M., Naccarato, M. E., Parker, K. C. H., \&Moskowitz, G.B. (2001). The personal need for structure and personal fear of invalidity measures; Historical perspectives, current applications, and future directions. In: G.B. Moskowitz (Ed.), Cognitive social psychology: The Princeton symposium on the legacy and future of social cognition. Hillsdale. NJ: Erlbaum, 19-40, draft version

Yüksel-Şahin F. (2008). Mathematics anxiety among 4th and 5th-grade Turkish elementary school students. Int Electronic J Math Educ., 3, 179-192. 